\title{
Electromechanical analysis of optimal trigger delays for cardiac MRI
}

\author{
Glenn S Slavin ${ }^{1 *}$, Maggie Fung ${ }^{2}$ \\ From 17th Annual SCMR Scientific Sessions \\ New Orleans, LA, USA. 16-19 January 2014
}

\section{Background}

Single-phase cardiac MRI acquires data only during a brief period of the cardiac cycle. To avoid motion artifacts, the operator must select a trigger delay that corresponds to a period of minimal cardiac motion, typically at end-systole or mid-diastole. This can be done by inspecting a prior cine scan for quiescent periods. However, because these cardiac phases can vary in temporal position and duration as a function of heart rate, another option should be available if the heart rate at the time of the single-phase scan differs from that during the cine scan. The goal of this work was to analytically determine the optimal trigger delays for cardiac MRI.

\section{Methods}

An electromechanical analysis of Wiggers diagram was used to determine the trigger delays (time after Rwave) at which systolic and diastolic quiescence begin (Figure 1).

\section{Systole}

End-systolic quiescence occurs during isovolumic relaxation, but due to the averaging effect of the data acquisition window, reduced heart motion appears slightly earlier. Also, because $20 \%$ of the stroke volume is ejected during the last $1 / 3$ of the LV ejection time (LVET) [1], it is assumed here that minimal cardiac motion actually begins during the last $1 / 6$ of LVET. Thus, the optimal systolic trigger delay $\mathrm{T}_{\text {sys }}$ should occur at $5 / 6$ (83\%) of LVET. From Figure 1a, $\mathrm{T}_{\text {sys }}=\mathrm{IVC}+0.83^{*} \mathrm{LVET}$, where LVET $=\mathrm{QS} 2$ $\mathrm{Q}_{\text {onset }} \mathrm{R}_{\text {peak }}$ - IVC. Using the substitutions IVC $=40 \mathrm{~ms}$ [2], $\mathrm{QS} 2=541-2.2 * \mathrm{HR}$ [3], and $\mathrm{Q}_{\text {onset }} \mathrm{R}_{\text {peak }}=40 \mathrm{~ms}$ [4], this gives $\mathrm{T}_{\text {sys }}=423-1.826^{*} \mathrm{HR}$ (where $\mathrm{HR}$ is heart rate in beats per minute).

GE Healthcare, Bethesda, Maryland, USA

Full list of author information is available at the end of the article

\section{Diastole}

End-diastolic quiescence occurs during diastasis, but for MRI scans, sufficiently reduced motion can begin $50 \mathrm{~ms}$ earlier [5]. Thus, the optimal diastolic trigger delay $\mathrm{T}_{\text {dias }}$ begins $50 \mathrm{~ms}$ prior to the end of rapid filling $\left(\mathrm{T}_{\text {rapid }}\right)$. From Figure $1 \mathrm{~b}, \mathrm{~T}_{\text {dias }}=\mathrm{QS} 2-\mathrm{Q}_{\text {onset }} \mathrm{R}_{\text {peak }}+\mathrm{IVR}+\mathrm{T}_{\text {rapid }}-50$. Using the above substitutions with IVR $=80 \mathrm{~ms}[6]$ and $\mathrm{T}_{\text {rapid }}=313-0.957 * \mathrm{HR}$ [7], this gives $\mathrm{T}_{\text {dias }}=894-$ $3.157 * \mathrm{HR}$. These models were compared with ECG-gated short-axis cine scans from 87 adult patients that were retrospectively studied to identify the systolic and diastolic trigger delays at which minimal heart motion began. To assess the efficacy of the equations in a clinical population, only patients with significant akinesis or dyskinesis were excluded. $T_{\text {dias }}$ was recorded only for patients exhibiting discernible periods of diastasis.

\section{Results}

Figure 2 plots measured trigger delay versus heart rate. Excellent agreement is seen between the regression lines for systolic and diastolic data and the values predicted by the equations.

\section{Conclusions}

Although previous studies have presented general quantitative relationships between various heart phases and heart rate, this work derives recommended trigger delays specifically for use with single-phase cardiac MRI. The models demonstrate good agreement with clinical results and can be valuable for automatically selecting optimal trigger delays when the heart rate varies during an exam or when no reference images are available.

\section{Funding}

N/A. 

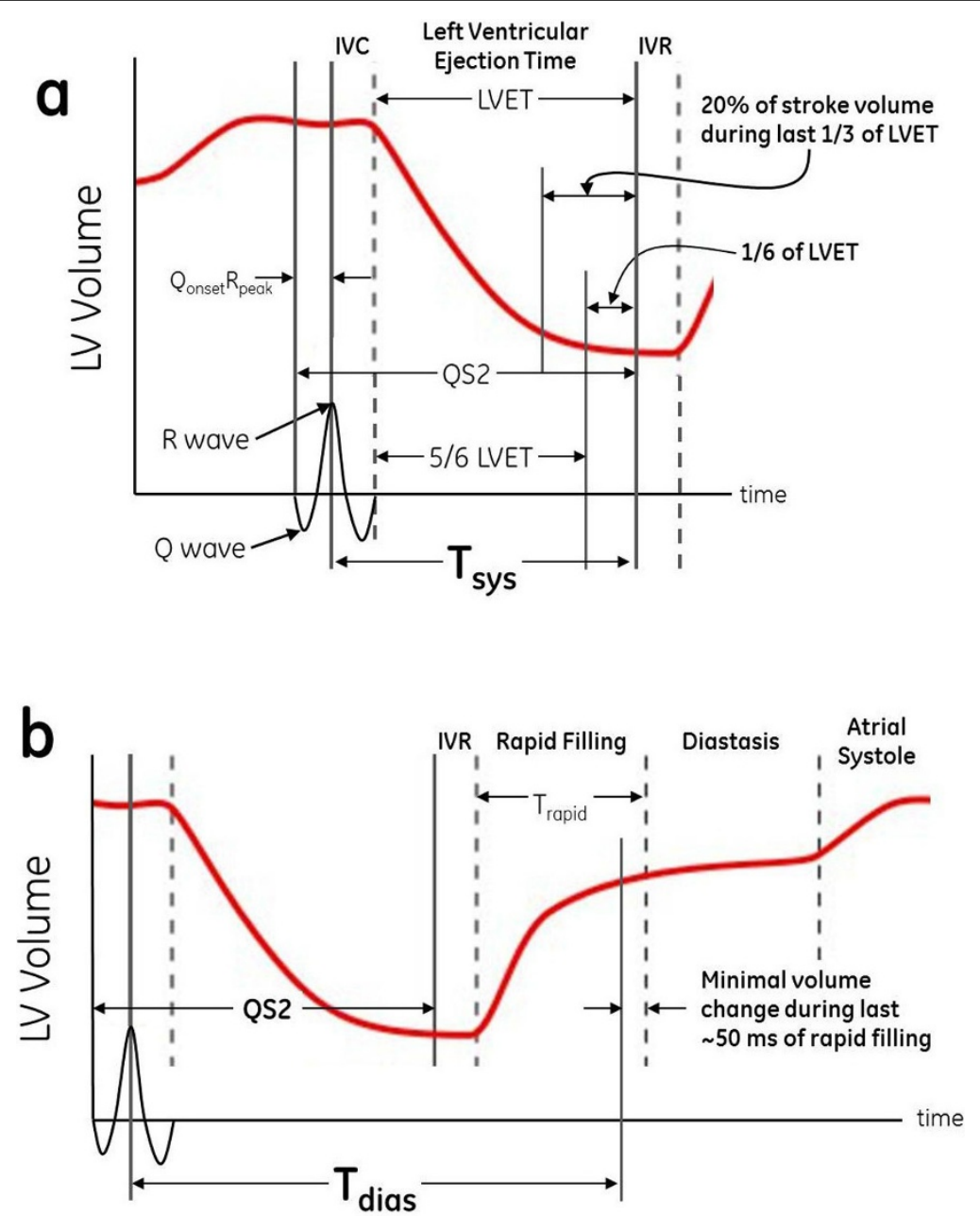

Figure 1 Left ventricular volume graphs from Wiggers diagram demonstrating optimal trigger delays for single-phase cardiac MRI. (a) Minimal systolic motion begins during the last 1/6 of LVET, when the left ventricular volume change is small. $T_{\text {sys }}=I V C+5 / 6 L V E T$, where LVET $=$ QS2 - $Q_{\text {onset }} R_{\text {peak }}$ - IVC. (b) Minimal diastolic motion begins slightly before the end of the rapid filling phase. $T_{\text {dias }}=$ QS2 - Q onset $R_{\text {peak }}+$ IVR $+T_{\text {rapid }}-50$.

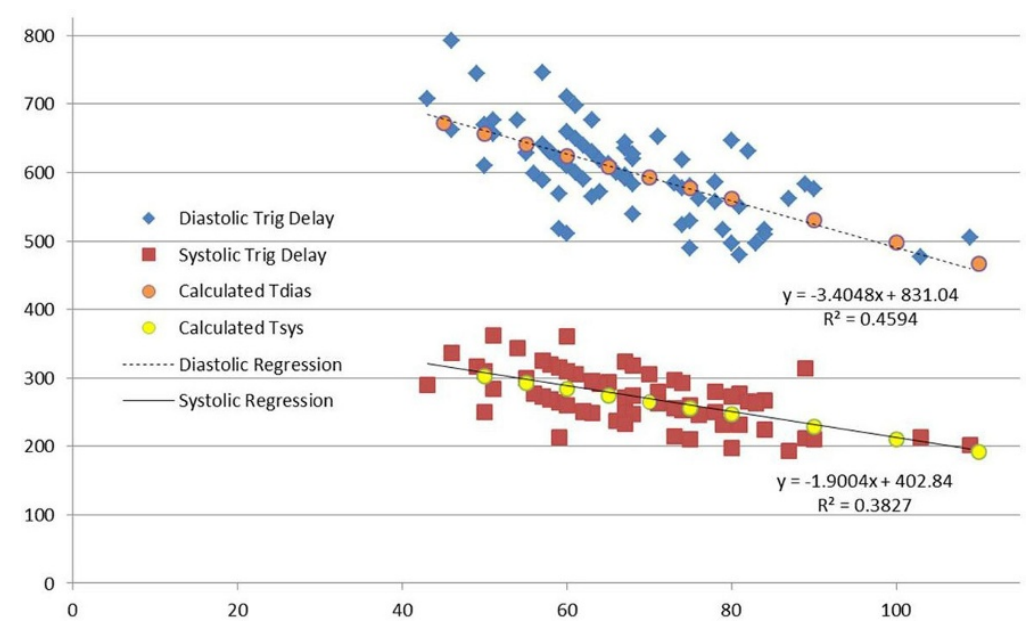

Figure 2 Plot of trigger delay versus heart rate. The predicted systolic and diastolic trigger delays show excellent agreement with the regression lines from the clinical measurements. 


\section{Authors' details}

${ }^{1}$ GE Healthcare, Bethesda, Maryland, USA. ${ }^{2}$ GE Healthcare, New York, New York, USA.

Published: 16 January 2014

\section{References}

1. Johnson: Circ 1975, 52:378.

2. Hirschfield: Circ 1976, 54:751.

3. Boudoulas: Chest 1981, 80:613.

4. Goldberger: J Appl Physiol 1983, 54:1083.

5. Bowman: Am J Physiol Heart Circ Physiol 2004, 287:H1650.

6. Lind: Eur J Echocardiography 2004, 5:284.

7. Chung: Am J Physiol Heart Circ Physiol 2004, 287:H2003.

doi:10.1186/1532-429X-16-S1-P73

Cite this article as: Slavin and Fung: Electromechanical analysis of optimal trigger delays for cardiac MRI. Journal of Cardiovascular Magnetic Resonance 2014 16(Suppl 1):P73.

Submit your next manuscript to BioMed Central and take full advantage of:

- Convenient online submission

- Thorough peer review

- No space constraints or color figure charges

- Immediate publication on acceptance

- Inclusion in PubMed, CAS, Scopus and Google Scholar

- Research which is freely available for redistribution

Submit your manuscript at www.biomedcentral.com/submit
C Biomed Central 